\title{
Partial baroreceptor dysfunction and low plasma nitric oxide bioavailability as determinants of salt-sensitive hypertension: a reverse translational rat study
}

\author{
A.S. Rodríguez-Pérez¹, J.F. López-Rodríguez ${ }^{1}$, M.Z. Calvo-Turrubiartes ${ }^{1}$, V.M. Saavedra-Alanís², \\ L. Llamazares-Azuara ${ }^{3}$ and M. Rodríguez-Martínez ${ }^{1}$ \\ ${ }^{1}$ Integrative Physiology Laboratory, Department of Physiology and Biophysics, \\ ${ }^{2}$ Molecular Biology Laboratory, Department of Biochemistry, and \\ ${ }^{3}$ Renal Laboratory, Faculty of Medicine, Autonomous University of San Luis Potosí, San Luis Potosí, Mexico
}

\begin{abstract}
This study determined whether clinical salt-sensitive hypertension (cSSHT) results from the interaction between partial arterial baroreceptor impairment and a high-sodium (HNa) diet. In three series (S-I, S-II, S-III), mean arterial pressure (MAP) of conscious male Wistar ChR003 rats was measured once before (pdMAP) and twice after either sham (SHM) or bilateral aortic denervation (AD), following 7 days on a low-sodium (LNa) diet (LNaMAP) and then 21 days on a HNa diet (HNaMAP). The roles of plasma nitric oxide bioavailability ( $\mathrm{pNOB}$ ), renal medullary superoxide anion production (RMSAP), and mRNA expression of $\operatorname{NAD}(P) H$ oxidase and superoxide dismutase were also assessed. In SHM $(n=11)$ and $A D(n=15)$ groups of S-I, LNaMAP-pdMAP was $10.5 \pm 2.1$ vs $23 \pm 2.1 \mathrm{mmHg}(\mathrm{P}<0.001)$, and the salt-sensitivity index (SSi; HNaMAP-LNaMAP) was $6.0 \pm 1.9$ vs $12.7 \pm 1.9 \mathrm{mmHg}(P=0.03)$, respectively. In the SHM group, all rats were normotensive, and $36 \%$ were salt

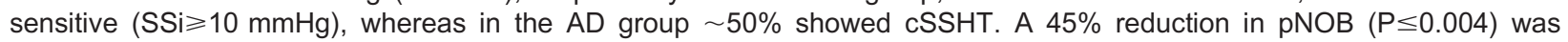
observed in both groups in dietary transit. RMSAP increased in the AD group on both diets but more so on the HNa diet $(\mathrm{S}-\mathrm{II}, \mathrm{P}<0.03)$ than on the $\mathrm{LNa}$ diet $(\mathrm{S}-\mathrm{III}, \mathrm{P}<0.04)$. MAP modeling in rats without a renal hypertensive genotype indicated that the $A D^{*} \mathrm{HNa}$ diet interaction $(P=0.008)$ increases the likelihood of developing cSSHT. Translationally, these findings help to explain why subjects with clinical salt-sensitive normotension may transition to cSSHT.
\end{abstract}

Key words: Salt-sensitive hypertension; Aortic barodenervation; Nitric oxide bioavailability

\section{Introduction}

Salt sensitivity is a condition in susceptible normotensive or hypertensive individuals in which a significant and sustained rise in mean arterial pressure (MAP) accompanies chronic high sodium chloride (salt) intake (1). Clinically, the difference in MAP between the ends of salt depletion and repletion regimes (acute or chronic), or vice versa, is called the salt-sensitivity index (SSi). This is a normally distributed, inherited trait used to classify an individual as salt sensitive (SS) if the value is $\geqslant 10 \mathrm{mmHg}$, as indeterminate (IND) if the value is $>5<10 \mathrm{mmHg}$, or as salt resistant (SR) if the value is $\leq 5 \mathrm{mmHg}$ (2). In addition, SS subjects exhibit a characteristically blunted slope in pressure-natriuresis or in pressure-Na diet relationships, whereas SR subjects do not (3). Experimentally, however, no defined protocol exists for identifying the SS condition as clinically defined. Thus, animals that show any increase in MAP induced by high salt intake, especially if MAP reaches the hypertensive range, are considered to have "experimental" SS hypertension (eSSHT). To our knowledge, the "clinical" concept of SS normotension (cSSNT) does not exist in the experimental field.

Studies of renal cross-transplantation between Dahl SS and Dahl SR rats performed by Dahl et al. (4), Dahl and Heine (5), and Morgan et al. (6), using both normal $(0.3 \%, \mathrm{NNa})$ and high $(8.0 \%, \mathrm{HNa})$ sodium diets, allowed them to arrive at two conclusions that others have come to endorse $(7,8)$. They concluded that eSSHT in Dahl SS rats is determined by the hypertensive genotype of the

Correspondence: M. Rodríguez-Martínez, Department of Physiology and Biophysics, Faculty of Medicine, Universidad Autónoma de San Luis Potosí, Av. V. Carranza, 2405, Bellas Lomas, 78210, San Luis Potosí, Mexico. E-mail: rodrigum@uaslp.mx 
kidney, which reduces the renal sodium excretory capacity (4-6), and by the systemic genotype of the rat, which determines how systemic factors (almost exclusively extrarenal) respond to a $\mathrm{HNa}$ diet (6). These systemic factors would further reduce the renal sodiumexcretory capacity of the kidney, which would be overcome only by further increasing MAP (7). To date, research has implicated several differential systemic factors in Dahl SS and Dahl SR rats. Among them are adrenal steroidogenesis (9), sympathetic nerve activity $(7,10)$, and endothelial function $(11,12)$.

In Dahl SS rats on a low salt diet $(0.04 \%, \mathrm{LNa})$ and, therefore, in a prehypertensive state, Gordon and Mark $(10,13)$ demonstrated a partial arterial baroreceptor impairment ( $v s$ Dahl SR rats on a LNa diet) that translated into a diminution of both the heart rate $(\mathrm{HR})$ and the neurosympathetic-mediated hindlimb vascular resistance baroreflex sensitivities, without altering the baseline MAP. They proposed that this partial impairment, the most common form of baroreceptor impairment (14), might amplify the effects of the $\mathrm{HNa}$ diet by failing to adequately buffer increases in arterial pressure (13). However, to our knowledge, this interaction has not been explored. If such an interaction exists, partial baroreceptor impairment might be one of the phenotypic elements of the SS systemic genotype (its baroreceptor element). On the other hand, it has been documented in Dahl SS rats (vs Dahl SR rats) that a $\mathrm{HNa}$ diet induces endothelial dysfunction, as manifested by increased vascular superoxide anion production (12), with reduction in both the plasma levels of nitrogen oxides (11) - an index of nitric oxide (NO) bioavailability - and in the endothelium-dependent relaxation to acetylcholine (12). If such interaction between endothelium and salt exists, endothelial dysfunction might constitute another of the phenotypic elements of the SS systemic genotype (its endothelial element).

The present study, performed in primarily normotensive rats, had two objectives: 1) to test the effects of sequential exposure, first to a LNa diet for 7 days and then to a $\mathrm{HNa}$ diet for 21 days, in rats with and without partial arterial baroreceptor impairment (to simulate the prehypertensive SS baroreceptor systemic phenotype) on SSi and on MAP after 21 days on a $\mathrm{HNa}$ diet, and 2) to study the roles of plasma NO bioavailability ( $\mathrm{pNOB}$ ), renal medullary superoxide anion production, and renal mRNA expression of $\mathrm{NAD}(\mathrm{P}) \mathrm{H}$ oxidase and superoxide dismutase (SOD) in such responses. We hypothesized that clinical saltsensitive hypertension (cSSHT) should develop in all rats on a $\mathrm{HNa}$ diet with partial arterial baroreceptor impairment, if in effect an interaction between them exists.

\section{Material and Methods}

\section{Series I, II, and III}

Male rats bred from the Wistar Charles River strain 003 (ChR003; Charles River, USA) were used in three series (S-I, S-II, and S-III). The effects of sequential exposure, first to a LNa diet for 7 days and then to a $\mathrm{HNa}$ diet for 21 days, in rats with and without chronic bilateral aortic denervation (partial barodenervation), on MAP, SSi, and pNOB were tested in S-I, and on baseline and NADHstimulated renal medullary superoxide anion production (RMSAP) and renal mRNA expression of $N A D(P) H$ oxidase and SOD at the end of a $\mathrm{HNa}$ diet in S-II. S-III tested the effects of a LNa diet for 7 days in rats with real or sham aortic denervation at baseline and NADHstimulated RMSAP. All experimental procedures were conducted in accordance with the Mexican Guidelines for the Care and Use of Experimental Animals (NOM-062Z00-1999).

\section{General protocol}

Weaned rats (70 to $90 \mathrm{~g}$ ) housed individually at the animal care facility (with an automated 12:12-h light-dark cycle, temperature, and humidity control) were weighed daily and had free access to a NNa diet (LabDiet 5P14, $0.4 \% \mathrm{Na}$, PMI Nutrition International, Inc., USA) and $0.9 \%$ isotonic saline as drinking water, to produce conditions for the expression or not of a renal hypertensive genotype. When rats reached $200-235 \mathrm{~g}$ body weight, MAP was measured when the rats were in a conscious state before aortic denervation [predenervation MAP (pdMAP)]. Next, rats were randomly assigned to sham (SHM) or real aortic denervated $(A D)$ groups. After barodenervation, they were returned to the animal care facility, having free access to the $\mathrm{NNa}$ diet plus filtered tap water until recovering their predenervation weight. Then, rats were exposed freely and in succession to a LNa diet $(0.04 \% \mathrm{Na}$, TD90228 diet, Harlan Teklad, USA) for 7 days, followed by a HNa diet ( $8 \%$ $\mathrm{Na}$, TD92012 diet, Harlan Teklad) for 21 days. MAP was measured again in the conscious state at the end of both $\mathrm{LNa}$ and $\mathrm{HNa}$ dietary regimes in S-I and S-II (3 occasions in total: pdMAP, LNaMAP, and HNaMAP) and at the end of the LNa dietary regime in S-III (2 occasions in total: pdMAP and LNaMAP).

\section{Predenervation measurement of MAP}

A catheter was implanted into the tail artery using aseptic techniques while the rat was under short-duration ether anesthesia. Once conscious, rats received $570 \mathrm{mg} / \mathrm{kg}$ metamizole sodium (PiSA, Mexico) sc and were placed in a very well-ventilated, semirestrictive (permitting back and forth movement), comfortable, low-stress rat holder (i.e., not a Lucite restrainer or Perspex tube). After a 4-h stabilization period, MAP and HR were recorded continuously for $60 \mathrm{~min}$. Then, rats received $90 \mathrm{mg} / \mathrm{kg}$ sodium ceftriaxone (Amcef, AMSA, Mexico) ia and were subjected to sham or real aortic denervation.

\section{Aortic barodenervation procedure}

Using aseptic techniques and after administering ip ketamine (33.3 mg/kg; Anesket, PiSA) and xylazine 
(6.7 mg/kg; Rompun, Bayer, Mexico) anesthesia, atropinized $(0.05 \mathrm{mg} / \mathrm{kg}$ ip; Atropisa, PiSA) rats were subjected to either sham or real chronic bilateral aortic barodenervation using Krieger's technique (15) slightly modified by us (16). Sham or real barodenervations lasted $30-40 \mathrm{~min}$. After tail and neck incisions were closed, rats received $570 \mathrm{mg} / \mathrm{kg}$ metamizole sodium $s c$ and were warmed until they became conscious. Over the subsequent 3 postsurgical days, rats received $140 \mathrm{mg} / \mathrm{kg}$ sodium ceftriaxone $\mathrm{im}$.

\section{Postdenervation measurement of MAP}

Twenty-four hours before measuring LNaMAP and HNaMAP, under aseptic conditions and with the rat under ether anesthesia, catheters were inserted into either the right femoral artery to record LNaMAP or the left femoral artery and vein to record HNaMAP and drug administration. Catheters exited the interscapular region and passed through a lightweight flexible spring to a $360^{\circ}$ rotary dispositive mounted above the cage. Then, $320,000 \mathrm{IU} / \mathrm{kg}$ penicillin $\mathrm{G}$ benzathine (Pendiben L-A, PiSA) im and $570 \mathrm{mg} / \mathrm{kg}$ metamizole sodium sc were administered. The next day, the rat was placed in the holder, the flexible spring was removed, and the arterial catheter was connected to a P23 XL transducer (Gould, USA). After a 30-min stabilization period beginning at 7:00 am, MAP and HR were recorded continuously for $60 \mathrm{~min}$. In S-I and S-II, after measuring LNaMAP, $1.5 \mathrm{~mL}$ arterial blood was collected in sterile and ice-cooled tubes without replacement. After removing the catheter(s) and over the subsequent 3 postsurgical days, rats received 80,000 IU/day penicillin G benzathine $\mathrm{im}$.

After measurement of HNaMAP in S-I and S-II and LNaMAP in S-III, $1.5 \mathrm{~mL}$ arterial blood was collected again and replaced with a $750-\mu \mathrm{L}$ bolus of $6 \%$ hydroxystarch solution (Hestar, PiSA) administered slowly iv. After a 30-min stabilization period, a subprotocol was performed to evaluate the effectiveness of aortic denervation. This consisted of recording MAP and HR for $1 \mathrm{~min}$ before (control) and 4 min after administering three 100$\mu \mathrm{L}$ boluses of phenylephrine at 10-min intervals [PHE; $10 \mu \mathrm{g} / \mathrm{kg} \mathrm{iv;} \mathrm{P-6126,} \mathrm{Sigma-Aldrich} \mathrm{Química} \mathrm{(S-AQ),}$ Mexico] and three $100-\mu \mathrm{L}$ boluses of sodium nitroprusside at 6-min intervals (SNP; $5 \mu \mathrm{g} / \mathrm{kg} \mathrm{iv}$; S-0501, S-AQ).

\section{MAP recording settings}

Blood pressure was recorded by coupling the P23 XL transducer to a 79D Grass polygraph (Grass Instrument Co., USA) via Grass 7P1-7DA amplifiers. The pulsatile waveform signal was led (via J1-J2) to another Grass 7DA amplifier to obtain the MAP value by electronic attenuation (0.1) and to a Grass 7P4 tachograph to record the instantaneous HR. Both signals (MAP and HR) were digitized at $2 \mathrm{~Hz}$ using a Data Translation DT 2801 analog-digital board with the HP-Vee software (HewlettPackard Co., USA). The difference between LNaMAP and pdMAP was calculated for each animal. MAP lability was measured as the standard deviation of the MAP recordings made of each conscious rat (7200 samples) over $1 \mathrm{~h}$ after either 7 days on the LNa diet (S-III) or 21 days on the $\mathrm{HNa}$ diet (S-I and S-II). The SSi was calculated as the difference between HNaMAP and LNaMAP.

\section{Effectiveness of aortic barodenervation}

The effectiveness of aortic barodenervation was evaluated in the conscious state using the transformed general sensitivity index (TGSI) previously described and validated by us (16). This index allows us to differentiate, on an individual basis, among rats with sham, aortic, or sino-aortic barodenervation: TGSI $=[(\{[3-(\Delta \mathrm{HRSNP}-$ $\Delta$ HRPHE/ $\triangle$ MAPSNP- $\triangle$ MAPPHE $\left.\left.\left.)]^{-0.4}\right\}-1\right) /-0.04597\right]$. TGSI ranges previously established (16) were as follows: for sham barodenervation, 10.09 to 11.46 ; for aortic denervation, 8.40 to 9.94 , and for sino-aortic denervation, 7.68 to 8.24 .

\section{Termination of the experiment}

At the end of the experiment, all rats in the three series were anesthetized with $50 \mathrm{mg} / \mathrm{kg}$ ip sodium pentobarbitone (Pentovet, Norvet, Mexico). Using aseptic techniques, a retrograde PE50 catheter (Intramedic, Clay Adams, USA) was inserted into the abdominal aorta near the iliac bifurcation and advanced to just below the left renal artery. This catheter was connected to a cold packwrapped 20-mL syringe containing ice-cold PBS, $\mathrm{pH} 7.4$, which was placed in an infusion pump (model 901, Harvard Apparatus Co., USA). Then, in rapid sequence, the infusion pump was turned on (at a $2.5 \mathrm{~mL} / \mathrm{min}$ infusion rate to hold a perfusion pressure at $\sim 110 \mathrm{mmHg}$ ); first, the left renal vein was transected, then the right renal vein was transected, and the proximal (caval) ends of the veins were knotted. Next, the mesenteric artery and upper aortic artery were knotted so that perfusion continued until the kidneys blanched ( $\sim 15 \mathrm{~min})$. Both kidneys were removed, placed in separate Petri boxes with ice-cold PBS, decapsulated, and sectioned longitudinally (frontal plane) in three slices. The left and right renal medullas were excised from the middle slices.

\section{Measurement of pNOB}

pNOB was measured as total plasma nitrogen oxide concentration $\left(\left[\mathrm{NO}_{x}\right] \mathrm{p}=\left[\mathrm{NO}_{2}+\mathrm{NO}_{3}\right] \mathrm{p}\right)$ using Griess's colorimetric reaction as described by Miranda et al. (17) but adapted by us for a microtube and $540 \mathrm{~nm}$ doublebeam spectrophotometer assay (DMS-70 UV-Vis; Varian, Australia). The change in plasma $\mathrm{NO}$ bioavailability $(\triangle \mathrm{pNOB})$ was calculated as $\mathrm{LNa}\left[\mathrm{NO}_{\mathrm{x}}\right] \mathrm{p}-\mathrm{HNa}\left[\mathrm{NO}_{\mathrm{x}}\right] \mathrm{p}$.

\section{Measurement of RMSAP}

Baseline and NADH-stimulated RMSAP were measured in S-II and S-III, as described by Guzik and Channon (18). About $100 \mathrm{mg}$ renal medulla in $2 \mathrm{~mL}$ icecold PBS lysis buffer [final concentrations: 1\% NP40 
(11332473001, Roche, Mexico), $0.5 \%$ sodium deoxycolate (D-6750, S-AQ), 0.1\% SDS (1610300, BioRad, USA), $1 \mathrm{mM} P M S F$ (P-7626, S-AQ), $10 \mathrm{U} / \mathrm{mL}$ aprotinin (A-1153, S-AQ), and $10 \mathrm{mM}$ sodium orthovanadate (B-49203, SAQ)] was homogenized and centrifuged at $4{ }^{\circ} \mathrm{C}$ at $14,835 \mathrm{~g}$ for 15 min (model RMC14, Sorvall, USA), and then the supernatant was cooled on ice. Next, under dark conditions, clean vials were counted (5 min) in a liquid scintillation counter (RackBeta, model 1209, Pharmacia Wallac Oy, Finland) in out-of-coincidence mode to obtain background (BKG) counts. To measure NADH-stimulated RMSAP, we counted $950 \mu \mathrm{L}$ of a mixture [4500 $\mu \mathrm{L}$ lysis buffer plus $250 \mu \mathrm{L} 10 \mu \mathrm{M}$ lucigenin (B49203, S-AQ)] and obtained the baseline (BL) count. Then, $50 \mu \mathrm{L}$ supernatant, $20 \mu \mathrm{L} 100 \mu \mathrm{M}$ NADH (N8129, S-AQ), and finally $20 \mu \mathrm{L}$ $400 \mathrm{U} / \mathrm{mL}$ SOD (S7571, S-AQ) were added in succession and counted each time. The same procedure was used to measure the BL RMSAP but without adding NADH. All measurements were done in duplicate. Homogenate protein concentration was measured by Bradford's method at $595 \mathrm{~nm}$. For each replicate, the integral of the counts per minute (cpm) for the last 4.5 min was obtained for BKG, $\mathrm{BL}, \mathrm{NADH}$, and SOD, and the duplicates were averaged. From the last three integrals, BKG was subtracted to obtain $\triangle \mathrm{BL}, \triangle \mathrm{NADH}$, and $\triangle \mathrm{SOD}$. We calculated RMSAP as follows: $\mathrm{BL}=\Delta \mathrm{BL}-\Delta \mathrm{SOD} / \mathrm{mg}$ protein, and $\mathrm{NADH}$ stimulated $=(\Delta \mathrm{NADH}-\Delta \mathrm{SOD})-(\Delta \mathrm{BL}-\Delta \mathrm{SOD}) / \mathrm{mg}$ protein .

Semiquantitative reverse-transcription PCR (RT-PCR)

Renal medulla was homogenized in a mixture of phenol and guanidine isothiocyanate (TRIzol, 15596-026, Invitrogen, USA) using a Polytron PT 1200 (Kinematica, Switzerland) and stored at $-80^{\circ} \mathrm{C}$ until the processing of total RNA extraction. RT reactions were performed using $2 \mu \mathrm{g}$ total RNA and a Superscript II Reverse Transcriptase kit in a $20-\mu \mathrm{L}$ mixture reaction. PCR was performed using the PTC-100 Programmable Thermal Controller system (MJ Research, USA) with a Platinum Taq DNA polymerase kit (10966, Invitrogen) using $1 \mu \mathrm{g}$ cDNA containing $0.2 \mathrm{mM}$ of each dNTP (18427, Invitrogen) in a $25-\mu \mathrm{L}$ mixture reaction. The reaction was incubated at $95^{\circ} \mathrm{C}$ for $5 \mathrm{~min}$, and 35 cycles of the following sequential steps were performed: $94^{\circ} \mathrm{C}$ for $30 \mathrm{~s}$, $58^{\circ} \mathrm{C}$ for $40 \mathrm{~s}$, and $72^{\circ} \mathrm{C}$ for $90 \mathrm{~s}$. The $\beta$-actin control was processed under the same conditions but for only 23 cycles. The number of cycles for each cDNA was previously determined by an amplification curve. The rat sense and antisense primer sequences shown in Table 1 were designed using the gene-specific sequence deposited in the GenBank. Ten-microliter aliquots were electrophoresed on a $2.5 \%$ agarose gel and visualized with the Gel Logic 100 Imaging System (Kodak, USA) using ethidium bromide. The densitometric band values for gp91phox, p22phox, intra-cytoplasmic (IC)-SOD, and $\beta$ actin were obtained using the Image $\mathrm{J}$ software $\mathrm{V} 1.43$ and were reported as relative band intensities.

\section{Experimental design and statistical analysis}

The three series were designed as cross-sectional studies because, even though in S-I and S-II the MAP and pNOB were measured at least two times in each rat (longitudinal subprotocols), the main response variables in such series were differences (SSi or $\triangle \mathrm{pNOB}$ ). MAP data in $\mathrm{S}-\mathrm{I}$ were first analyzed $(95 \% \mathrm{Cl})$ by linear mixedeffects models (19) to evaluate the denervation*diet interaction and by ANCOVA to evaluate the effects of pdMAP and group on LNaMAP. Thereafter, SSi and HNaMAP data in S-I were modeled by multiple regression (linear fixed models, $95 \% \mathrm{Cl}$ ) using re-parametrized variables. The residuals of the models were tested for normality (Shapiro-Wilk test) and homoscedasticity (Brown-Forsythe test) (20). When necessary, the data were subjected to a Box-Cox transformation to adhere to the assumptions of parametric statistics. The best models were chosen on the basis of the highest adjusted $r^{2}$ (determination coefficient $=$ explained variation), the lowest Akaike information criterion (21), the likelihood ratios, and the principle of parsimony. Post hoc multiple comparisons were performed by the Tukey test. MAP data in S-II were analyzed by multivariate analysis of variance (MANOVA) with repeated measures for the diet factors. In the three series, as necessary, classical parametric tests for nonindependent and independent samples were used. All values are reported as means $\pm S E$, and data were analyzed using the JMP V.7.01 software (SAS Institute, USA) and the R V 2.14.1 software.

\section{Results}

\section{Series}

Body weight time course in SHM and AD groups. Only 26 of 36 sham or real aortic denervated rats showed a satisfactory body weight evolution and fulfilled the TGSI barodenervation criteria (SHM group, $n=11$ and $A D$ group, $n=15)$. Despite randomization, predenervation body weight was modestly $(\sim 7 \mathrm{~g})$ but significantly greater $(P<0.02$, unpaired $t$-test) in the $A D$ group than in the SHM group (Table 2). The AD group showed a greater decrease in body weight $(\sim 17 \mathrm{~g}$ more, $\mathrm{P}=0.001$, unpaired $t$-test) requiring a longer recovery time than the SHM group to reach its predenervation body weight $(\sim 3$ days more, $P=0.001$, unpaired $t$-test). However, at the end of the $\mathrm{LNa}$ diet and the $\mathrm{HNa}$ diet, both groups had similar body weights.

Pre- and postdenervation MAP time courses in SHM and $A D$ groups. Table 3 shows the pdMAP, LNaMAP, and HNaMAP recorded in each group. Since preliminary experiments in $S H M$ and $A D$ rats showed stable urinary sodium excretions of $\sim 0$ and $\sim 30 \mathrm{mEq}$ /day with the LNa and $\mathrm{HNa}$ diets, respectively, LNaMAP and HNaMAP are plotted in Figure 1 as pressure-sodium diet relationships. There was no difference in pdMAP between groups, and 
Table 1. Oligonucleotide sequences for forward $(F)$ and reverse $(R)$ primers $\left(5^{\prime}-3^{\prime}\right)$.

\begin{tabular}{|c|c|c|c|c|}
\hline Gene & Sequence & $\begin{array}{l}\text { Location of } \\
\text { product (bp) }\end{array}$ & $\begin{array}{c}\text { GenBank } \\
\text { accession No. }\end{array}$ & $\begin{array}{c}\text { Product } \\
\text { length (bp) }\end{array}$ \\
\hline \multirow[t]{2}{*}{ gp91phox } & F 5'-AAAGGAGTGCCCAGTACCAAAGT-3' & $762-784$ & AF298656 & 78 \\
\hline & R 5'-TACAGGAACATGGGACCCACTAT-3' & $839-817$ & & \\
\hline \multirow[t]{2}{*}{ p22phox } & F 5'-AACTGACCGCTGTGGTGAA-3' & $259-277$ & U18729 & 68 \\
\hline & R 5'-GTGGAGGACAGCCCGGA-3' & $326-310$ & & \\
\hline \multirow[t]{2}{*}{ IC-SOD } & F 5'-TGTGTCCATTGAAGATCGTGT-3' & $384-406$ & NM-017050 & 84 \\
\hline & R 5'-TCTTGTTTCTCGTGGACCACC-3' & $467-447$ & & \\
\hline \multirow[t]{2}{*}{$\beta$-actin } & F 5'-TCATGAAGTGTGACGTTGACATCCGT-3' & $926-951$ & M-031144 & 285 \\
\hline & R 5'-CCTAGAAGCATTTGCGGTGCACGATG-3' & $1210-985$ & & \\
\hline
\end{tabular}

gp91phox and p22phox are subunits of NAD(P)H oxidase; IC-SOD: intra-cytoplasmic superoxide dismutase.

the TGSI value showed a statistically significant difference $(\mathrm{P}=0.001$, unpaired $t$-test) between groups. MAP during the LNa diet increased above the pdMAP value in both groups, but more so in the AD group $(23 \pm 2.1 \mathrm{mmHg})$ than in the SHM group $(10.5 \pm 2.1 \mathrm{mmHg})$. The difference between LNaMAP and pdMAP was $12.5 \mathrm{mmHg}$ greater $(P=0.001$, unpaired $t$-test) in the $A D$ group than in the SHM group (Figure 1). The modeling of LNaMAP by ANCOVA indicated that $50 \%$ of the variation in LNaMAP $\left(r^{2}=0.4987\right.$, ANOVA $\left.P=0.001\right)$ could be explained by the pdMAP and group predictor variables, without any interaction between them. Moreover, after 21 days on the $\mathrm{HNa}$ diet, MAP increased relative to its corresponding LNaMAP, but to a lesser extent in the SHM group (SSi: $6.0 \pm 1.9 \mathrm{mmHg}$; an SSi of the IND subtype; see later) than in the AD group $(12.7 \pm 1.9 \mathrm{mmHg}$; an SSi of the SS subtype; see later). The difference between SSi values was statistically significant $(P=0.03$, unpaired $t$-test) as were the HNaMAP values (SHM: $118.8 \pm 1.9$ vs AD: $135.0 \pm 2.1 \mathrm{mmHg}, \mathrm{P}=0.001$, unpaired $t$-test). The modeling of these MAP data by linear mixed models $\left(r^{2}=0.6791\right)$ showed effects of pdMAP $(P=0.002$, chisquare test), denervation ( $P=0.001$, chi-square test), diet $(P=0.001$, chi-square test), and a clear denervation*diet interaction ( $P=0.008$, chi-square test).

SSi, frequency of SSi subtypes, and hypertension in $S H M$ and $A D$ groups. The SSi in each group fitted a normal distribution (Shapiro-Wilk test), and each rat was stratified to any of the three SSi subtypes described in humans (2). Given that the standard deviation of HNaMAP in the SHM group $(n=11)$ was $6.30 \mathrm{mmHg}$, $95.4 \%$ of the sample values fell between 106.2 and $131.3 \mathrm{mmHg}$ ( \pm 2 standard deviations). Accordingly, a cut-off value of $\geqslant 130 \mathrm{mmHg}$ was chosen to indicate the presence of hypertension under our experimental conditions (e.g., substrain used, age of the rats, or use of the low-stress rat holder). Figure 2 shows the frequencies of SSi subtypes in both groups. In the SHM group, most of the rats $(64 \%)$ showed either an SR or IND subtype, but, unexpectedly, 36\% showed an SS subtype. In this group, $50 \%$ of SR rats decreased their MAP on the $\mathrm{HNa}$ diet (Figure 2, inverted arrows). In contrast, in the AD group only $60 \%$ of the rats showed an SS subtype and $67 \%$ were hypertensive ( $\geqslant 130 \mathrm{mmHg}$ ). The hypertensive rats in this group represented $77 \%$ of the SS subtype rats, $50 \%$ of the IND subtype rats, and $50 \%$ of the SR subtype rats. Globally, $\sim 50 \%$ of the rats in the AD group developed cSSHT ( $S \mathrm{Si} \geqslant 10 \mathrm{mmHg}$ plus HNaMAP $\geqslant 130 \mathrm{mmHg}$ ). Moreover, the $\mathrm{HNa}$ diet increased HNaMAP in all rats of the AD group, regardless of their SSi subtype. Finally, we found a modest yet significant association between SSi and HNaMAP ( $r=0.7088, P=0.001$, Pearson).

Total plasma nitrogen oxide concentration $\left(\left[\mathrm{NO}_{x}\right] \mathrm{p}\right)$ on $\mathrm{LNa}$ and $\mathrm{HNa}$ diets. Independent of the group, we found that $\left[\mathrm{NO}_{\mathrm{x}}\right] \mathrm{p}$ levels fell significantly $(45 \%, \mathrm{P} \leq 0.004$, paired $t$-test) from the LNa to HNa diet Figure 3). Thus, in both

Table 2. Evolution of body weight in SHM and AD groups of series I.

\begin{tabular}{lllllll}
\hline Group & pd bw $(\mathrm{g})$ & $\min$ bw $(\mathrm{g})$ & $\Delta$ bw $(\mathrm{g})$ & $\mathrm{RT}($ days $)$ & 7 days LNa bw $(\mathrm{g})$ & 21 days HNa bw $(\mathrm{g})$ \\
\hline SHM $(\mathrm{n}=11)$ & $207 \pm 1.9$ & $196 \pm 2.1$ & $11 \pm 1.0$ & $3 \pm 0.2$ & $242 \pm 4.6$ & $348 \pm 10.0$ \\
AD $(\mathrm{n}=15)$ & $215 \pm 2.3^{*}$ & $186 \pm 2.5^{*}$ & $28 \pm 1.7^{* *}$ & $6 \pm 0.4^{* *}$ & $255 \pm 6.0$ & $337 \pm 9.0$ \\
\hline
\end{tabular}

Data are reported as means \pm SE. pd bw: predenervation body weight; min bw: minimum body weight reached by the rats after denervation; $\Delta \mathrm{bw}$ : change in body weight after denervation (pd bw minus min bw); RT: recovery time (days after denervation for recovering its pd bw); 7 days LNa bw: body weight after 7 days on low-sodium diet; 21 days HNa bw: body weight after 21 days on highsodium diet; SHM: sham chronic aortic bilateral denervation group; $\mathrm{AD}$ : renal chronic aortic bilateral denervation group. ${ }^{*} \mathrm{P}=0.02$, ${ }^{* *} \mathrm{P}=0.001$ vs SHM group (unpaired $t$-test). 
Table 3. Pre- and postdenervation mean arterial pressure, MAP lability, salt-sensitivity index, and transformed general sensitivity index, in SHM and AD groups of series I.

\begin{tabular}{lccccccc}
\hline Group & $\begin{array}{c}\text { pdMAP } \\
(\mathrm{mmHg})\end{array}$ & $\begin{array}{c}\text { LNaMAP } \\
(\mathrm{mmHg})\end{array}$ & $\begin{array}{c}\text { LNaMAP_pdMAP } \\
(\mathrm{mmHg})\end{array}$ & $\begin{array}{c}\text { HNaMAP } \\
(\mathrm{mmHg})\end{array}$ & $\begin{array}{c}\text { SD of MAP } \\
(\mathrm{mmHg})\end{array}$ & $\begin{array}{c}\text { SSi } \\
(\mathrm{mmHg})\end{array}$ & $\begin{array}{c}\text { TGSI } \\
(\mathrm{w} / \mathrm{o} \text { units })\end{array}$ \\
\hline $\mathrm{SHM}(\mathrm{n}=11)$ & $102.3 \pm 2.4$ & $112.8 \pm 1.5^{+}$ & $10.5 \pm 21$ & $118.8 \pm 1.9^{+\#}$ & $2.5 \pm 0.2$ & $6.0 \pm 1.9$ & $10.9 \pm 0.1$ \\
$\mathrm{AD}(\mathrm{n}=15)$ & $99.3 \pm 2.1$ & $122.3 \pm 1.7^{+\beta}$ & $23.0 \pm 2.1^{\beta}$ & $135.0 \pm 2.1^{+*}$ & $5.4 \pm 0.4^{\beta}$ & $12.7 \pm 1.9^{\alpha}$ & $9.3 \pm 0.2^{\beta}$ \\
\hline
\end{tabular}

Data are reported as means \pm SE. MAP: mean arterial pressure; pdMAP: predenervation MAP; LNaMAP: postdenervation MAP after 7 days on low-sodium diet; LNaMAP-pdMAP: LNaMAP minus pdMAP; HNaMAP: postdenervation MAP after 21 days on high-sodium diet; SD of MAP: standard deviation of MAP as index of MAP lability; SSi: salt-sensitivity index; TGSI: transformed general sensitivity index (adimensional, validated index of effectiveness of barodenervation); SHM: sham chronic aortic bilateral denervated group; AD: real chronic aortic bilateral denervated group; ${ }^{+} \mathrm{P}=0.001 \mathrm{vs} \mathrm{pdMAP}$ (paired $t$-test); ${ }^{*} \mathrm{P}=0.005,{ }^{*} \mathrm{P}=0.001 \mathrm{vs} \mathrm{LNaMAP}$ (paired $t$-test); ${ }^{\alpha} \mathrm{P}=0.03,{ }^{\beta} \mathrm{P}=0.001$ vs SHM group (unpaired $t$-test).

groups, the difference in $\left[\mathrm{NO}_{\mathrm{x}}\right] \mathrm{p}$ between $\mathrm{LNa}$ and $\mathrm{HNa}$ diets $\left(\Delta\left[\mathrm{NO}_{\mathrm{x}}\right] \mathrm{p}\right)$ was positive and similar, indicating that the two groups had similar reductions in plasma $\mathrm{NO}$ bioavailability (positive $\triangle$ pNOB). The $\triangle$ pNOB fitted a normal distribution in both groups (Shapiro Wilk test) but did not show any association with SSi $(r=0.0031$, $P=0.99$, Pearson) or HNaMAP $(r=0.031, P=0.87$, Pearson).

Modeling of SSi and HNaMAP. When TGSI was taken as an index of the extent of barodenervation (16) and the $\triangle \mathrm{pNOB}$ was taken as an index of the change in sodium diet, the modeling of SSi (by multiple regression) indicated that $\sim 60 \%$ of the variation in SSi $\left(r^{2}=0.5730\right.$; ANOVA $\mathrm{P}=0.003$ ) could be explained by the predictor variables

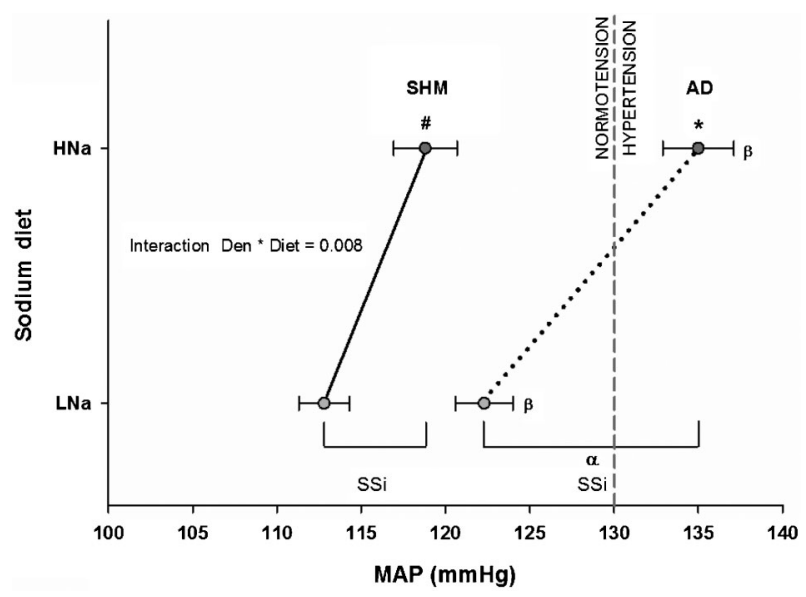

Figure 1. Pressure-sodium diet relationship constructed from the postdenervation mean arterial pressure (MAP) measured after 7 days on the low-sodium diet (LNaMAP) and after 21 days on the high-sodium diet (HNaMAP) in each group of Series I. The saltsensitivity index (SSi) for each group is indicated, as is the MAP threshold (gray dashed line $=130 \mathrm{mmHg}$ ) for hypertension (see Results). SHM: sham group; AD: aortic denervated group; Den: denervation. Data are reported as means $\pm S E$. ${ }^{\#} P=0.005$, ${ }^{*} \mathrm{P}=0.001$ vs LNaMAP (paired $t$-test); ${ }^{\alpha} \mathrm{P}=0.03,{ }^{\beta} \mathrm{P}=0.001$ vs SHM group (unpaired $t$-test).
TGSI $(\beta=-4.357 ; \quad P=0.003 ;$ power $=92 \%), \quad \Delta$ pNOB $(\beta=-0.2986 ; \quad P=0.62 ;$ power $=8 \%)$, and the $\mathrm{TGSI}^{*} \triangle \mathrm{pNOB}$ interaction $(\beta=1.6297 ; \mathrm{P}=0.02$; power $=70 \%$ ). In contrast, the reduction of this model (SSi) leaving only TGSI as the predictor variable, reduced the $r^{2}$ to 0.2368 (ANOVA $\mathrm{P}=0.02$; power $74 \%$ ). Moreover, the modeling of HNaMAP (by multiple regression) indicated that $\sim 99 \%$ of the variation in HNaMAP $\left(r^{2}=0.9999 ;\right.$ ANOVA $\left.P=0.001\right)$ could be explained by the predictor variables LNaMAP $(\beta=1.000$; $\mathrm{P}<0.001$; power $=100 \%)$ and the SSi $(\beta=1.000$; $\mathrm{P}<0.001$; power $=100 \%$ ), with no interaction between them.

Renal medullary mRNA expression of IC-SOD and $N A D(P) H$ oxidase subunits. After 21 days on a $\mathrm{HNa}$ diet (Figure 4), there were no differences between groups in the renal medullary mRNA expression of the two $\mathrm{NAD}(\mathrm{P}) \mathrm{H}$ oxidase subunits studied, and that of IC-SOD was $30 \%$ lower in the AD group than the SHM group, although the latter fell short of statistical significance $(\mathrm{P}=0.06$, unpaired $t$-test).

\section{Series II}

RMSAP at the end of the HNa diet. Six of 8 rats in the SHM group and all 8 rats in the AD group fulfilled TGSI criteria. The behavior of TGSI, pdMAP, LNaMAP, LNaMAPpdMAP, and HNaMAP in S-II was similar to that shown for those variables in S-I, except that the SSi difference between groups fell short of statistical significance, likely due to the elimination of two SHM experiments $(\mathrm{SHM}=7.4 \pm 2.8$ vs $\mathrm{AD}=12.8 \pm 3.4 \mathrm{mmHg})$. At the end of the $\mathrm{HNa}$ diet, there was no difference in baseline RMSAP $(\sim 215,000 \mathrm{cpm})$ between the groups. The NADHstimulated RMSAP in the SHM group with respect to its baseline RMSAP exhibited a near 4-fold increase $(697,075 \pm 120,208 \mathrm{cpm} / \mathrm{mg}$ protein, $\mathrm{P}<0.006$, paired $t$-test), whereas the AD group exhibited a corresponding near 9-fold increase $(1,908,498 \pm 490,274 \mathrm{cpm} / \mathrm{mg}$ protein, $\mathrm{P}<0.004$, paired $t$-test). NADH-stimulated RMSAP was $180 \%$ greater in the $A D$ group than in the SHM group $(\mathrm{P}<0.03$, unpaired $t$-test, right bars in Figure 5). 

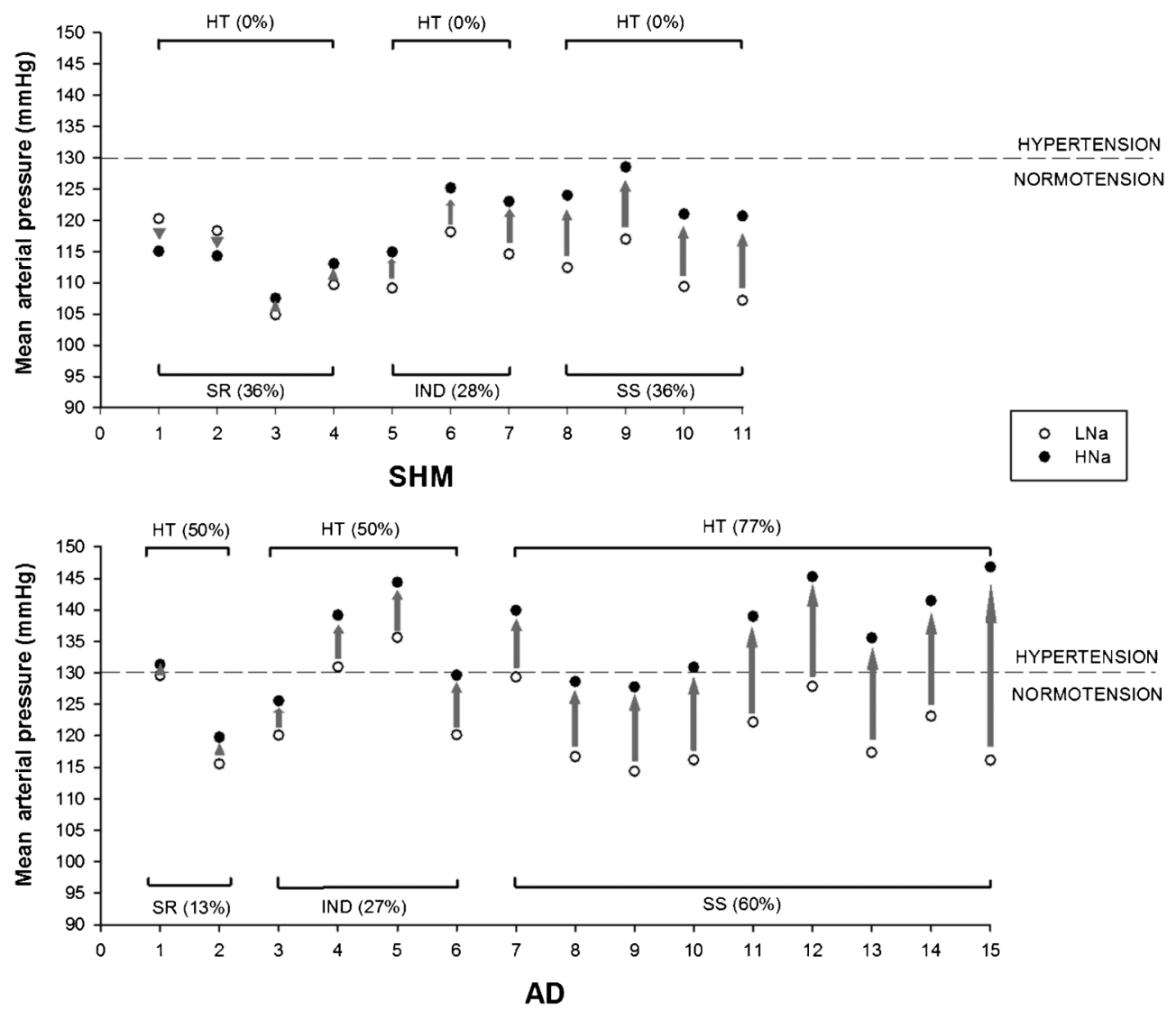

Figure 2. Distribution of frequencies of the three subtypes of SSi (SS, IND, and SR) in SHM $(n=11)$ and AD ( $n=15)$ groups of Series I. Each experiment in both groups is represented by one number on the x-axis. The magnitude of vertical distance between the open circles (LNa diet) and the solid circles (HNa diet) for each rat represents its individual SSi value. Up or down arrows or arrowheads denote increased or decreased MAP on the HNa diet. Frequency of hypertension ( $\mathrm{HT}: \mathrm{MAP} \geqslant 130 \mathrm{mmHg}$ ) is indicated for each subtype of SSi observed. SHM: sham group; AD: aortic denervated group; LNa: low-sodium diet; HNa: high-sodium diet; HT: hypertension; SR: salt resistant; IND: indeterminate; SS: salt-sensitive subtypes of SSi (salt-sensitivity index).

\section{Series III}

RMSAP at the end of the LNa diet. Six of 8 rats in the SHM group and all 8 rats in the AD group fulfilled TGSI criteria. The behavior of TGSI, pdMAP, LNaMAP, and LNaMAP-pdMAP in S-III was similar to that shown for those variables in S-I and S-II. The SSi was not calculated in this series because the experiments ended after 7 days on the LNa diet, and at that time, there was no difference between the groups in baseline RMSAP $(\sim 270,000 \mathrm{cpm})$. In the SHM group, the NADH-stimulated RMSAP $(296,397 \pm 144,430 \mathrm{cpm} / \mathrm{mg}$ protein, not significant, paired t-test) was the same as its corresponding baseline RMSAP, whereas in the AD group this variable was different from its baseline RMSAP (887,520 \pm $254,074 \mathrm{cpm} / \mathrm{mg}$ protein, $\mathrm{P}<0.02$, paired $t$-test). The $\mathrm{NADH}$-stimulated RMSAP was $\sim 200 \%$ greater $(\mathrm{P}<0.04$, unpaired $t$-test, left bars in Figure 5 ) in the AD group than in the SHM group. Since the study was not primarily designed to evaluate differences in baseline or $\mathrm{NADH}$ stimulated RMSAP between a HNa diet (S-II) and a LNa diet (S-III) in either the SHM or AD group, the interseries RMSAP data are not strictly comparable. This limitation notwithstanding, the NADH-stimulated RMSAP (Figure 5) was significantly greater $(\mathrm{P}<0.03$, unpaired $t$-test) in $\mathrm{S}$-II, after 7 days on the LNa diet plus 21 days on the $\mathrm{HNa}$ diet (right bars), than in S-III, after only 7 days on the LNa diet (left bars).

\section{Discussion}

The principal findings of this study performed in male Wistar rats bred from the ChR003 substrain were the following: 1) the SS subtype of the SSi was present in $36 \%$ of the rats in the SHM group and in $60 \%$ of the rats in the $A D$ group; 2) independent of the group and $S S i$ subtype, the change from a LNa to a HNa diet significantly reduced plasma NO bioavailability (positive $\triangle \mathrm{pNOB}$ ); 3 ) under a LNa diet, chronic bilateral aortic denervation induced a significant rightward shift of MAP; 4) the interaction between chronic bilateral aortic denervation 


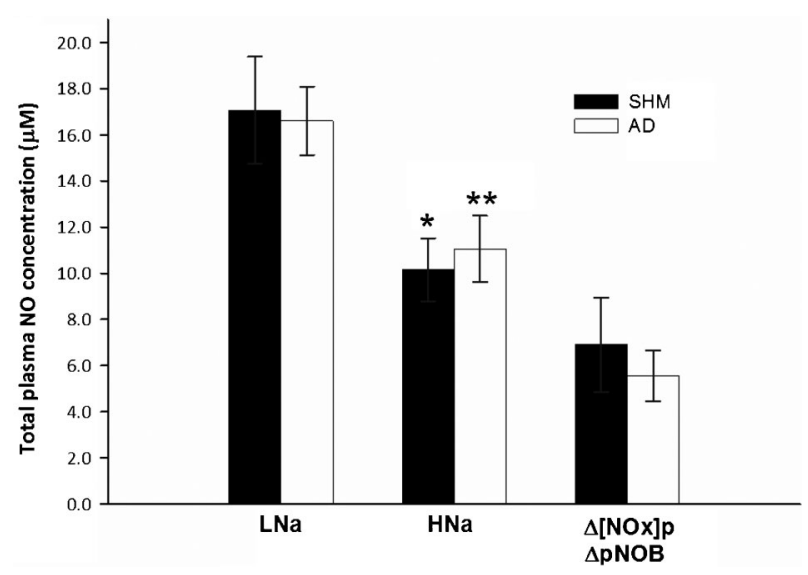

Figure 3. Total plasma nitrogen oxide concentration [NOx]p in both groups of Series I after 7 days on the low-sodium ( $\mathrm{LNa}$ ) diet and 21 days on the high-sodium $(\mathrm{HNa})$ diet in succession $(n=10)$. [NOx]p is equivalent to plasma NO bioavailability (pNOB); $\Delta[N O x] p$ or $\Delta p N O B$ is the difference in [NOx]p or pNOB between $\mathrm{LNa}$ and $\mathrm{HNa}$ diets. A positive difference means reduction in [NOx]p or pNOB during $\mathrm{HNa}$ vs $\mathrm{LNa}$ diet. SHM: sham group; AD: aortic denervated group. Data are reported as means \pm SE. ${ }^{*} \mathrm{P}=0.004,{ }^{*} \mathrm{P}=0.001$ vs $\mathrm{LNa}$ diet (paired $t$-tests).

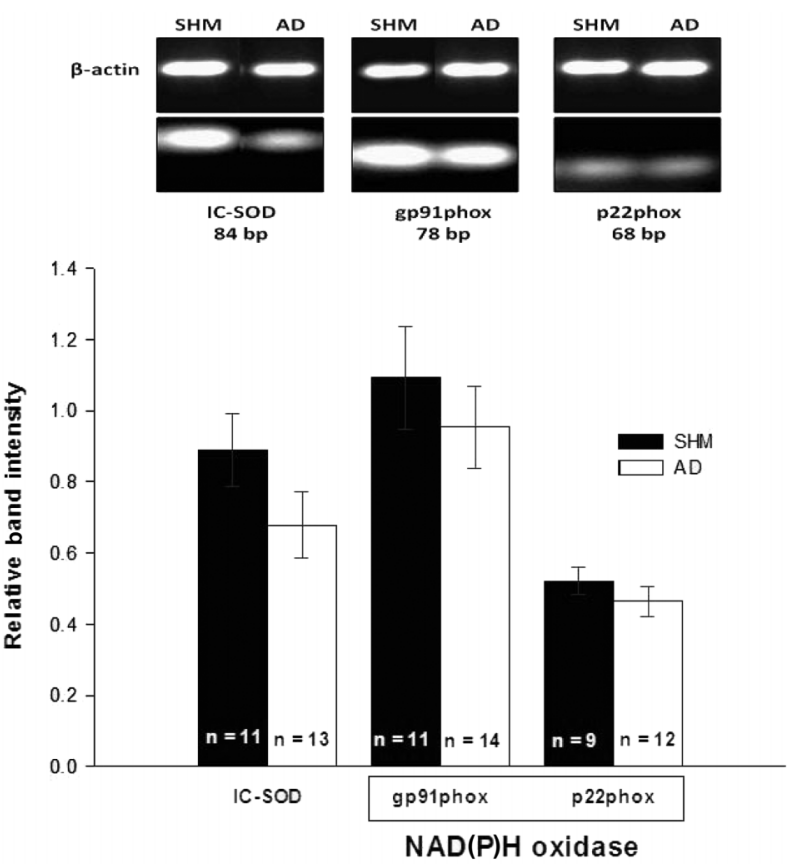

Figure 4. Renal medullary mRNA expression of IC-SOD, gp91phox and p22phox in Wistar ChR003 rats allocated to sham and aortic denervated groups of S-I after 21 days on the $\mathrm{HNa}$ diet. The difference between groups in mRNA expression of SOD was not significant $(\mathrm{P}=0.06$; unpaired $t$-test). $\mathrm{n}$ : number of experiments; IC-SOD: intra-cytoplasmic superoxide dismutase; gp91phox and p22phox are subunits of $\mathrm{NAD}(\mathrm{P}) \mathrm{H}$ oxidase; SHM: sham group; $A D$ : aortic denervated group. and the $\mathrm{HNa}$ diet induced a significant increase in SSi; 5) together, these last two events induced cSSHT in 50\% of the rats in the AD group; 6) under either a LNa diet or a $\mathrm{HNa}$ diet, aortic denervation increased renal medullary $\mathrm{NADH}$-stimulated superoxide anion production, although apparently the increase was greater in extent under a $\mathrm{HNa}$ diet; 7) after 21 days on the $\mathrm{HNa}$ diet, renal medullary expression of mRNA of the IC-SOD and of the gp91phox, and p22phox $\mathrm{NAD}(\mathrm{P}) \mathrm{H}$ oxidase subunits was not different between groups.

To find a HNaMAP of $119 \pm 1.9 \mathrm{mmHg}$ in 11 - to $12-$ week-old rats in the SHM group ( $\sim 350 \mathrm{~g}$ body weight) after two periods of salt loading (postweaning and postsham denervation), besides being similar to the MAP measured over $2 \mathrm{~h}$ by Franchini and Krieger (22) and Franchini et al. (23) in tethered, freely moving Wistar rats of $300 \mathrm{~g}(114 \pm 2 \mathrm{mmHg})$ and $250 \mathrm{~g}(118 \pm 4 \mathrm{mmHg})$ body weight, respectively, on a normal sodium diet, indicates that rats of the Wistar ChR003 substrain used in the present study do not carry a primary renal hypertensive genotype. Since rats are more resistant to salt than humans (24), a change of at least $10 \mathrm{mmHg}$ in SSi was imposed as a criterion to classify rats of the SS subtype. Thus, through a longitudinal, inductive and diagnostic subprotocol, it was found that the SSi fitted a normal distribution, and the frequency of the subtypes of SSi (SR, IND, or SS) within each group was documented (Figure 2). Unexpectedly, in the SHM group, 36\% of the rats were of the SS subtype, although all rats were normotensive. This demonstrates experimentally for the first time that the cSSNT (SSi $\geqslant 10 \mathrm{mmHg}$ plus $\mathrm{MAP}<130 \mathrm{mmHg}$ ) phenotype exists. Also unexpectedly, in the AD group only $60 \%$ of the rats were of the SS subtype and $67 \%$ of the rats developed hypertension, such that only $50 \%$ of the rats showed CSSHT $(S S i \geqslant 10 \mathrm{mmHg}$ plus $\mathrm{MAP} \geqslant 130 \mathrm{mmHg}$ ). Although the sample size was not large $(n=26$ rats), these SS frequencies are quite similar to those described in normotensive $(25 \%)$ and hypertensive $(50 \%)$ human subpopulations (2), which suggests that the present model in this rat substrain might recreate the salt sensitivity of humans. These results also suggest that $\mathrm{SS}$, as clinically defined ( $\mathrm{SSi} \geqslant 10 \mathrm{mmHg}$ ), could be an epiphenomenon of hypertension. Whether the cSSNT phenotype exists in other outbred or inbred rat strains or substrains (e.g., Dahl SR rats) is unknown, but this could be determined by performing a subprotocol similar to the one described here.

To simulate the prehypertensive SS baroreceptor systemic phenotype of partial baroreceptor impairment $(10,13)$, a chronic bilateral aortic denervation was performed instead of a chronic bilateral carotid sinus denervation, because the destruction of chemoreceptors during the carotid sinus denervation $(22,23)$ in a species like the rat, which lacks functional aortic body chemoreceptors (25), causes chronic hypoventilation with consequent chronic 


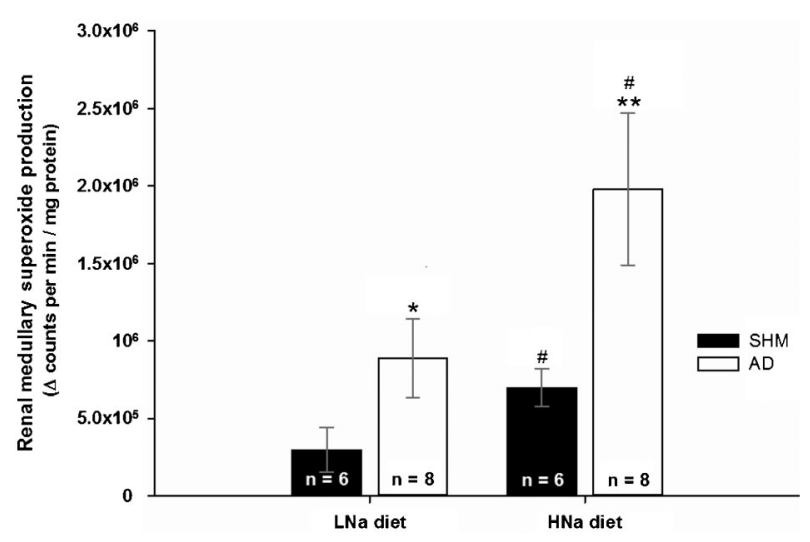

Figure 5. NADH-stimulated renal medullary superoxide anion production in SHM and AD groups of Series III (after only 7 days on the LNa diet, left bars) and of Series II (after 7 days on the LNa plus 21 days on the HNa diet, right bars). SHM: sham group; AD: aortic denervated group; $\mathrm{n}$ : number of experiments. Data are reported as means $\pm \mathrm{SE}$. ${ }^{*} \mathrm{P}=0.04,{ }^{* *} \mathrm{P}=0.03$ vs $\mathrm{SHM}$ group (unpaired $t$-tests); ${ }^{*} \mathrm{P} 0.03$ vs LNa diet (unpaired $t$-test).

systemic hypoxia, which in turn has the chronic effect of lowering blood pressure (23). In addition, the pdMAP was measured, and a validated individualized criterion of aortic barodenervation (TGSI) (16) was used in each rat. The general modeling of MAP data by mixed models showed that MAP differences between groups could be explained by the pdMAP, the effect of partial arterial barodenervation, the transition from a LNa to a HNa diet, and the interaction between partial arterial barodenervation and diet.

We showed that the AD group, after about 13 postdenervation days (including 7 days on the LNa diet) had a greater rightward shift in both absolute MAP (LNaMAP) and relative MAP (LNaMAP-pdMAP) than the SHM group, all absolute values being within the normotensive range $(<130 \mathrm{mmHg})$. The difference in absolute MAP (LNaMAP) between groups was $\sim 10 \mathrm{mmHg}$, which was the same difference between groups reported by Franchini and Krieger (22) in tethered, freely moving, 20day-post-aortic denervated Wistar rats on a normal sodium diet. Given that the modeling of LNaMAP data indicated that both the covariate pdMAP and group factor were their predictor variables, a number of factors might contribute to the observed absolute and relative changes in LNaMAP in our two groups: saline consumption from weaning to predenervation, the postdenervation recovery time, and the 7 days on the LNa diet. However, in the AD group it is also likely that chronic aortic denervation contributed significantly to the changes observed in LNaMAP.

The next question was: How durable is this LNaMAP rightward shift when $A D$ rats consume a $L N a$ diet? In the above-mentioned study by Franchini and Krieger (22), the $\sim 10 \mathrm{mmHg}$ MAP increase observed 20 days postdenervation was not different from the maximal value of $15 \mathrm{mmHg}$ observed in another group of rats evaluated 1 day after aortic denervation. However, no difference in absolute MAP $(104 \pm 2 \mathrm{mmHg})$ was reported by Van Vliet et al. (26) in telemetery data from freely moving, unstressed 6-week post-aortic denervated Long-Evans rats on a $\mathrm{NNa}$ diet when compared with a 6-week sham group (102 $\pm 1 \mathrm{mmHg}$ ). Similarly, previous unpublished longitudinal observations of our laboratory indicate that the MAP in conscious, aortic-denervated Wistar ChR003 rats fed a $\mathrm{NNa}$ diet the first 10 postdenervation days and then a LNa diet for the following 21 days $(116 \pm 2.3 \mathrm{mmHg})$ was not different from the MAP in the same rats $(n=10)$ measured before aortic denervation $(113.6 \pm 1.8 \mathrm{mmHg})$. Although direct evidence from continuous longitudinal studies is lacking, all these studies strongly suggest that, in the conscious aortic-denervated rat, after an early and maximum nonhypertensive MAP increase, MAP decreases gradually toward its predenervation value, with this process being apparently faster with a LNa diet (at most 4 weeks) than with a NNa diet (at most 6 weeks). For both diets, after 15 days of aortic denervation, the MAP is shifted to the right. It must be noted that Kline et al. (27) reported in tethered Wistar rats on a NNa diet that chronic renal denervation reversed the increase in MAP observed 19 days after aortic denervation, although that study lacked aortic denervation criteria. This limitation notwithstanding, such a study suggests that the observed rightward shift of LNaMAP in our AD group might be related to a rise in either baseline efferent or baseline afferent renal sympathetic nerve activity (RSNA) or in both. Finally, the modeling of HNaMAP explained almost entirely its variation and included as predictors variables to not only LNaMAP, as expected, but also to SSi. Thus, HNaMAP in the AD group is a mixed phenomenon composed of the already discussed rightward shift of LNaMAP plus the amplification of SSi (vs the SHM group) induced by the interaction of both aortic denervation and the change from a LNa diet to a HNa diet. All of this explains why this group showed a greater rightward shift of MAP on the $\mathrm{HNa}$ diet than on the $\mathrm{LNa}$ diet (and, therefore, an $\mathrm{SSi} \sim 7 \mathrm{mmHg}$ greater than the SHM group), with greater frequency of the SS subtype of SSi and cSSHT.

Comparison of this new model of cSSHT with the total arterial barodenervation model, comprised of sino-aortic denervation plus salt, which is the classical model of induced eSSHT, is almost inescapable. In 2-week postsino-aortic denervated and telemeterized, freely moving Sprague-Dawley rats, Osborn and Hornfeldt (28) measured MAP while the dietary sodium regime was changed from a NNa diet for 1 week to a progressive $\mathrm{HNa}$ diet (first $4 \%$ and then $8 \%$ ) during the next 6 weeks. Using the group's MAP lability as the criterion of barodenervation, they found no between-group differences in MAP during the $\mathrm{NNa}$ diet. However, during the $4 \%$ and $8 \% \mathrm{HNa}$ diets, MAP increased progressively more in the sinoaortic denervated group than in the sham group, so that, 
from 24-h averages, they found that at the end of the $8 \%$ $\mathrm{HNa}$ dietary regime, MAP had increased ( $v s$ the $\mathrm{NNa}$ diet) by $4 \pm 1 \mathrm{mmHg}$ in the sham group and $15 \pm 2 \mathrm{mmHg}$ in the sino-aortic denervated group (these values were not statistically compared in the article); the latter group achieved a maximal MAP lower than $130 \mathrm{mmHg}$. Even though Osborn and Hornfeldt (28) did not explicitly postulate the existence of an denervation*diet interaction, their data (HNaMAP-NNaMAP) strongly support its existence even under the very unusual stress-free conditions. The authors concluded that arterial baroreceptors play a major role in long-term control of MAP under the conditions of a $\mathrm{HNa}$ diet. The present study performed in rats under low-stress conditions (a more common condition) also demonstrates the existence of such an interaction, but in a model including partial baroreceptor impairment, a more common form of baroreceptor impairment than total sino-aortic denervation, which suggests that the interaction is independent of the stress conditions. On the other hand, in contrast to aortic denervation, sino-aortic denervation, as usually performed, also destroys carotid chemoreceptors and results in hypoventilation, which by itself induces chronic hypoxia with its consequent chronic lowering of blood pressure $(22,23)$. This last fact alone could explain why Osborn and Hornfeldt (28) did not find differences between groups in MAP on a $\mathrm{NNa}$ diet and why the maximal sino-aortic denervation group's MAP levels did not exceed $130 \mathrm{mmHg}$. In other words, our AD model likely allowed us to observe the LNaMAP differences between groups and a HNaMAP of $>130 \mathrm{mmHg}$ by avoiding the confounding hypotensive effects of sinoaortic denervation-induced hypoxia. Alternatively, these latest changes in our $A D$ model might be, in addition, the result of both the interaction between $A D$ and the use of a low-stress rat holder (LNaMAP differences) and the interactions among $A D$, the use of a low-stress rat holder, and a $\mathrm{HNa}$ diet (HNaMAP differences). Identifying which is the case is a task left to those research groups with available telemetric systems.

In the present study, the $\mathrm{HNa}$ diet reduced $\mathrm{pNOB}$ compared to the LNa diet (positive $\triangle \mathrm{pNOB}$ ). This pattern was the opposite of that reported by Shultz and Tolins (29) (negative $\triangle \mathrm{sNOB}$ ) in intact Sprague-Dawley rats. Thus, there seem to be different $\mathrm{HNa}$ diet-responsive endothelial systemic genotypes among rat strains, with our rat substrain showing some degree of endothelial salt sensitivity (positive $\triangle \mathrm{pNOB}$ ), although this phenotype would not be exclusively extrarenal because kidneys also have blood vessels. Moreover, the SHM and AD groups had the same positive $\triangle \mathrm{pNOB}(\sim 45 \%)$ pattern, indicating that this change was not under aortic baroreflex control. Although the present work was not designed to study the mechanisms of a positive $\triangle \mathrm{pNOB}$, it is possible that this may be mediated by salt-induced endogenous inhibition of endothelial nitric oxide synthase and/or by increased availability of vascular superoxide due to increased production and/or to reduced degradation (30). Furthermore, because both $\triangle \mathrm{pNOB}$ and SSi were affected by the dietary change, SSi was remodeled in terms of $\triangle \mathrm{pNOB}$. Interestingly, this modeling indicated that $\sim 60 \%$ of its variation could be better explained by TGSI (which per se was negative and significantly associated with SSi), by the change in diet judged by $\triangle \mathrm{pNOB}$ (which per se was not associated with $\mathrm{SSi}$ ), and by the interaction between both (which per se was positive and significantly associated with SSi). These associations suggest that a positive $\triangle \mathrm{pNOB}$ in response to a $\mathrm{HNa}$ diet may be a necessary, but not sufficient factor for the expression of SSi. Moreover, the lack of association between $\triangle \mathrm{pNOB}$ and $\mathrm{SSi}$, coupled with the fact that only $36 \%$ and $60 \%$ of the rats in the SHM and AD groups, respectively, showed an SS subtype, indicates that a positive $\triangle \mathrm{pNOB}$ is not synonymous with the specific existence of the SS subtype. Furthermore, we found no association between $\triangle \mathrm{pNOB}$ and HNaMAP, notwithstanding the significant (although smaller than expected) association between SSi and HNaMAP $(r=0.7089)$. Even though, experimentally, Bayorh et al. (11) documented that a positive $\triangle \mathrm{pNOB}$ was found in Dahl SS (hypertensive) rats but not in Dahl SR (normotensive) rats, such results are difficult to interpret, because these authors did not evaluate the SSi, as we have done here. Therefore, it is unknown whether all Dahl SS rats have a clinical SS subtype or whether all Dahl SR rats have a clinical SR subtype. Evidently, the criterion used to define Dahl rats as SS or SR was based on whether or not the rats consistently developed hypertension on a HNa diet; however, our data show that hypertension on a HNa diet can coexist without a clinical SS subtype. In contrast, our results are consistent with clinical studies of Campese et al. (31) and Bragulat et al. (32), who showed a similar and positive $\triangle \mathrm{pNOB}$ in SS and SR hypertensive Afro-American and Spanish patients, respectively, all of whom were evaluated for SSi. However, our results are not consistent with the clinical results of Fang et al. (33), who found a positive $\triangle \mathrm{pNOB}$ only in SS but not in SR normotensive Chinese individuals, all of whom were evaluated for SSi. We do not currently have an explanation for these differences, although racial differences could play a role. What is clear is that a thorough investigation of SSi - at both experimental and clinical levels, in normotensive and hypertensive subjects of diverse strains, origins, lineages, and races - and its association with pNOB are mandatory.

Given that the renal medulla is critical for regulating blood pressure (34), and knowing the role played by free radicals in modulating both renal medullary blood flow (RMBF) and tubular functions (35), we first explored the effects of sequential exposure to a $\mathrm{LNa}(0.04 \% \mathrm{Na}$, for 7 days) diet followed by a $\mathrm{HNa}(8 \% \mathrm{Na}$, for 21 days) diet regime (S-II) in our model, and then the effects of isolated exposure to a $\mathrm{LNa}(0.04 \% \mathrm{Na})$ diet for 7 days (S-III) on RMSAP. We found a greater increase in NADH-stimulated 
RMSAP in the AD group than in the SHM group in both the LNa diet (S-III) and the HNa diet (S-I), although apparently the difference was greater during the $\mathrm{HNa}$ diet than the LNa diet. This contrasts with a recent study by Johns et al. (36), who found no difference in NADH-stimulated RMSAP in sham Wistar rats subjected to normal $(0.3 \%)$ and high (3\%) sodium diets. Thus, the difference in findings in the sham rats evaluated in these studies could be explained by the range of diets used (7.97 vs $2.7 \%$, respectively). Moreover, our findings strongly suggest that $\mathrm{NADH}$-stimulated RMSAP might be under the inhibitory control of aortic baroreceptors, suggesting again that this response could be mediated by an increase in baseline efferent RSNA. Our findings also suggest that this local RMSAP is increased by a $\mathrm{HNa}$ diet per se, and even more so when aortic denervation and a $\mathrm{HNa}$ diet are conjoined. This scenario, then, might constitute the functional background of the denervation*diet interaction indicated by the analysis. In that sense, Mattson et al. (37) reported that reductions in RMBF are capable of inducing chronic sodium retention and chronic increase of MAP in rats. Years later, Zou et al. (38) demonstrated in rats that renal medullary superoxide anions exert tonic renal medullary vasoconstrictive and antinatriuretic actions. Moreover, Eppel et al. (39) reported that, in anesthetized rabbits, stimulation of the renal nerves decreases RMBF in a frequency-dependent manner, and that the systemic inhibition of NO by L-NG-nitroarginine (represented in the present study by a positive $\mathrm{p} \Delta \mathrm{NOB}$ ) reduced baseline RMBF and revealed the RMBF-reducing effect of low-frequency renal nerve stimulation. It is possible, therefore, that aortic denervation, by increasing baseline efferent RSNA, might directly reduce RMBF - especially if there is concurrently a positive $\triangle \mathrm{pNOB}$ - but also indirectly by raising RMSAP, and even more so under a $\mathrm{HNa}$ diet.

Whatever the mechanism involved in the differential rise of RMSAP in the AD group on the $\mathrm{HNa}$ diet, this did not seem to affect, in S-I (Figure 4), the renal medullary mRNA expression of $\mathrm{NAD}(\mathrm{P}) \mathrm{H}$ oxidase subunits gp91phox or p22phox, although it tended to decrease the mRNA expression of IC-SOD in this group, suggesting that this mechanism first affects the mRNA expression of antioxidant enzymes and that it does not use Anglldependent mRNA expression of the p22phox NAD $(P) H$ oxidase subunit pathway for that purpose (40). However, we cannot rule out the possibility that such a mechanism could affect, at the translational or posttranslational level, the activities of these enzymes.

\section{References}

1. Sullivan JM. Salt sensitivity. Definition, conception, methodology, and long-term issues. Hypertension 1991; 17: I-61-I-68, doi: 10.1161/01.HYP.17.1_Suppl.I61.

2. Weinberger MH, Miller JZ, Luft FC, Grim CE, Fineberg NS. Definitions and characteristics of sodium sensitivity and blood pressure resistance. Hypertension 1986; 8: II-127-II-134,
In summary, in a process of reverse translation, the present study systematized in male Wistar ChR003 rats a longitudinal, inductive and diagnostic subprotocol ( 7 days on a LNa diet plus 21 days on a HNa diet) for obtaining to an experimental level the SSi, which is the most widely used clinical SS diagnostic tool. All SSi subtypes were found in both the SHM group (normotensive) and the AD group (mostly hypertensive), and the condition of cSSNT has been described for the first time in the intact rat, raising the possibility that SS is an epiphenomenon of hypertension. On the other hand, independently of aortic denervation status, the rats showed a $45 \%$ reduction in plasma NO bioavailability (positive $\Delta \mathrm{pNOB}$ ) when they changed from a $\mathrm{LNa}$ diet to a $\mathrm{HNa}$ diet, which was interpreted as indicating that this rat substrain shows some degree of endothelial salt sensitivity, and suggests that this sensitivity may be one of the constitutive elements of the SS systemic phenotype (the endothelial element). Moreover, the analysis indicated that, in primarily normotensive rats without a renal hypertensive genotype but under low-stress conditions (a more common condition than no-stress and induced here by using a rat holder), aortic denervation increased LNaMAP, but the interaction of aortic denervation with a $\mathrm{HNa}$ diet increased the likelihood of developing cSSHT, which supports the idea that partial baroreceptor impairment is one of the constitutive elements of the SS systemic phenotype (the baroreceptor element). Furthermore, it is reported for the first time that, while aortic denervation and a $\mathrm{HNa}$ diet each alone increased $\mathrm{NADH}$-stimulated RMSAP, together they might cause an even higher increase in RMSAP. The main translational implication of these findings is that they help to explain why subjects with cSSNT may transition to cSSHT.

\section{Acknowledgments}

Research supported by the Autonomous University of San Luis Potosí (grants \#C02-FAl-04-4.9, \#C03-FAl-116.41, \#C04-FAI-10-2.45, and \#C09-FAI-03.20.20), by the National Council of Science and Technology (grant CONACYT \#62282), and by Integrative Physiology Laboratory's own financial resources. A.S. RodríguezPérez received the CONACYT scholarship (\#167277) from February 2008 to January 2012, as well as the International Early Career Physiologist Travel Award for attending EB2011 (APS, 2011) to present part of this study.

doi: 10.1161/01.HYP.8.6 Pt 2.II127.

3. Campese VM. Salt sensitivity in hypertension. Renal and cardiovascular implications. Hypertension 1994; 23: 531550, doi: 10.1161/01.HYP.23.4.531.

4. Dahl LK, Heine M, Thompson K. Genetic influence of the kidneys on blood pressure. Evidence from chronic renal 
homografts in rats with opposite predispositions to hypertension. Circ Res 1974; 40: 94-101, doi: 10.1161/01.RES. 40.4.94.

5. Dahl LK, Heine M. Primary role of renal homografts in setting chronic blood pressure levels in rats. Circ Res 1975; 36: 692-696, doi: 10.1161/01.RES.36.6.692.

6. Morgan DA, DiBona GF, Mark AL. Effects of interstrain renal transplantation on $\mathrm{NaCl}$-induced hypertension in Dahl rats. Hypertension 1990; 15: 436-442, doi: 10.1161/01.HYP. 15.4.436.

7. Leenen FH, Ruzicka M, Huang BS. The brain and saltsensitive hypertension. Curr Hypertens Rep 2002; 4: 129135, doi: 10.1007/s11906-002-0037-y.

8. Rettig R, Grisk O. The kidney as a determinant of genetic hypertension: evidence from renal transplantation studies. Hypertension 2005; 46: 463-468, doi: 10.1161/01.HYP. $0000178189.68229 .8 \mathrm{a}$.

9. Saavedra JM, Del Carmine R, McCarty R, Guicheney P, Weise $\mathrm{V}$, Iwai $\mathrm{J}$. Increased adrenal catecholamines in saltsensitive genetically hypertensive Dahl rats. Am J Physiol 1983; 245: H762-H766.

10. Gordon FJ, Mark AL. Mechanism of impaired baroreflex control in prehypertensive Dahl salt-sensitive rats. Circ Res 1984; 54: 378-387, doi: 10.1161/01.RES.54.4.378.

11. Bayorh MA, Ganafa AA, Socci RR, Silvestrov N, Abukhalaf IK. The role of oxidative stress in salt-induced hypertension. Am J Hypertens 2004; 17: 31-36, doi: 10.1016/j.amjhyper. 2003.08.003.

12. Zhou MS, Schulman IH, Raij L. Vascular inflammation, insulin resistance, and endothelial dysfunction in saltsensitive hypertension: role of nuclear factor kappa B activation. J Hypertens 2010; 28: 527-535, doi: 10.1097/ HJH.0b013e3283340da8.

13. Gordon FJ, Mark AL. Impaired baroreflex control of vascular resistance in prehypertensive Dahl S rats. Am J Physiol 1983; 245: H210-H217.

14. Gribbin B, Pickering TG, Sleight P, Peto R. Effect of age and high blood pressure on baroreflex sensitivity in man. Circ Res 1971; 29: 424-431, doi: 10.1161/01.RES.29.4.424.

15. Krieger EM. Neurogenic hypertension in the rat. Circ Res 1964; 15: 511-521, doi: 10.1161/01.RES.15.6.511.

16. Rodríguez-Martínez M, Torres-Rodriguez ML, Brito-Orta MD, López-Rodríguez JF, Rodríguez-Pérez AS, CalvoTurrubiartes $\mathrm{MZ}$, et al. An improved strategy for evaluating the extent of chronic arterial baroreceptor denervation in conscious rats. Braz J Med Biol Res 2010; 43: 1062-1075, doi: 10.1590/S0100-879X2010007500097.

17. Miranda KM, Espey MG, Wink DA. A rapid, simple spectrophotometric method for simultaneous detection of nitrate and nitrite. Nitric Oxide 2001; 5: 62-71, doi: 10.1006/ niox.2000.0319.

18. Gusik TJ, Channon KM. Measurement of vascular reactive oxygen species production by chemiluminescence. In: Fennel JP, Baker AH (Editors), Methods in molecular medicine, Vol. 108: Hypertension: Methods and Protocols. Totowa: Humana Press Inc.; 2005. p 73-89.

19. Pinheiro JC, Bates DM. Linear mixed-effects models. In: Chambers J, Eddy W, Hardle W, Shether S, Tierney L (Editors), Mixed effects models in $S$ and S-Plus. New York: Springer-Verlag Inc.; 2000. p 3-52.

20. Heiberger RM, Holland B. Multiple regression - More than one predictor. In: Casella J, Fienberg S, Olkin I (Editors), Statistical analysis and data display: an intermediate course with samples in S-plus, $R$ and SAS. New York: Springer Science + Business Media Inc.; 2004. p 215-324.

21. Akaike HA. New look at the statistical model identification. IEEE Trans Automat Contr AC 1974; 19: 716-723, doi: 10.1109/TAC.1974.1100705.

22. Franchini KG, Krieger EM. Carotid chemoreceptors influence arterial pressure in intact and aortic-denervated rats. Am J Physiol 1992; 262: R677-R683.

23. Franchini KG, Cestari IA, Krieger EM. Restoration of arterial blood oxygen tension increases arterial pressure in sinoaortic-denervated rats. Am J Physiol 1994; 266: H1055-H1061.

24. O'Shaughnessy KM, Karet FE. Salt handling and hypertension. Annu Rev Nutr 2006; 26: 343-365, doi: 10.1146/ annurev.nutr.26.061505.111316

25. Sapru HN, Krieger AJ. Carotid and aortic chemoreceptor function in the rat. J Appl Physiol 1977; 42: 344-348.

26. van Vliet BN, Chafe LL, Montani JP. Contribution of baroreceptors and chemoreceptors to ventricular hypertrophy produced by sino-aortic denervation in rats. J Physiol 1999; 516 (Part 3): 885-895, doi: 10.1111/j.1469-7793. 1999.0885u.x.

27. Kline RL, Patel KP, Ciriello J, Mercer PF. Effect of renal denervation on arterial pressure in rats with aortic nerve transection. Hypertension 1983; 5: 468-475, doi: 10.1161/ 01.HYP.5.4.468.

28. Osborn JW, Hornfeldt BJ. Arterial baroreceptor denervation impairs long-term regulation of arterial pressure during dietary salt loading. Am J Physiol 1998; 275: H1558-H1566.

29. Shultz PJ, Tolins JP. Adaptation to increased dietary salt intake in the rat. Role of endogenous nitric oxide. J Clin Invest 1993; 91: 642-650, doi: 10.1172/JCl116244.

30. Banday AA, Muhammad AB, Fazili FR, Lokhandwala M Mechanisms of oxidative stress-induced increase in salt sensitivity and development of hypertension in SpragueDawley rats. Hypertension 2007; 49: 664-671, doi: 10.1161/ 01.HYP.0000255233.56410.20.

31. Campese VM, Tawadrous M, Bigazzi R, Bianchi S, Mann AS, Oparil S, et al. Salt intake and plasma atrial natriuretic peptide and nitric oxide in hypertension. Hypertension 1996; 28: 335-340, doi: 10.1161/01.HYP.28.3.335.

32. Bragulat E, de la Sierra A, Antonio MT, Coca A. Endothelial dysfunction in salt-sensitive essential hypertension. Hypertension 2001; 37: 444-448, doi: 10.1161/01.HYP. 37.2.444.

33. Fang Y, Mu JJ, He LC, Wang SC, Liu ZQ. Salt loading on plasma asymmetrical dimethylarginine and the protective role of potassium supplement in normotensive salt-sensitive Asians. Hypertension 2006; 48: 724-729, doi: 10.1161/ 01.HYP.0000238159.19614.ce.

34. Guyton AC, Hall JE, Coleman TG, Manning D. The dominat role of the kidneys in the long term regulation of arterial pressure in normal and hypertensive states. In: Laragh $\mathrm{JH}$, Brenner BM (Editors), Hypertension: pathophysiology, diagnosis and management. New York: Raven Press, Ltd.; 1990. p 1029-1051.

35. Cowley AW Jr. Renal medullary oxidative stress, pressurenatriuresis, and hypertension. Hypertension 2008; 52: 777786, doi: 10.1161/HYPERTENSIONAHA.107.092858.

36. Johns EJ, O'Shaughnessy B, O'Neill S, Lane B, Healy V. 
Impact of elevated dietary sodium intake on $\mathrm{NAD}(\mathrm{P}) \mathrm{H}$ oxidase and SOD in the cortex and medulla of the rat kidney. Am J Physiol 2010; 299: R234-R240.

37. Mattson DL, Lu S, Nakanishi K, Papanek PE, Cowley AW Jr. Effect of chronic renal medullary nitric oxide inhibition on blood pressure. Am J Physiol 1994; 266: H1918-H1926.

38. Zou AP, Li N, Cowley AW Jr. Production and actions of superoxide in the renal medulla. Hypertension 2001; 37:
547-553, doi: 10.1161/01.HYP. 37.2.547.

39. Eppel GA, Denton KM, Malpas SC, Evans RG. Nitric oxide in responses of regional kidney perfusion to renal nerve stimulation and renal ischaemia. Pflugers Arch 2003; 447: 205-213, doi: 10.1007/s00424-003-1149-1.

40. Wilcox CS. Oxidative stress and nitric oxide deficiency in the kidney: a critical link to hypertension? Am J Physiol 2005; 289: R913-R935. 